\title{
Menarcheal age of mothers and daughters: Tehran Lipid and Glucose Study
}

\author{
F.R. Tehrani, ${ }^{7}$ P.Mirmiran, ${ }^{7}$ S. Zahedi-Asl, ${ }^{7}$ K. Nakhoda ${ }^{7}$ and F. Azizi ${ }^{7}$
}

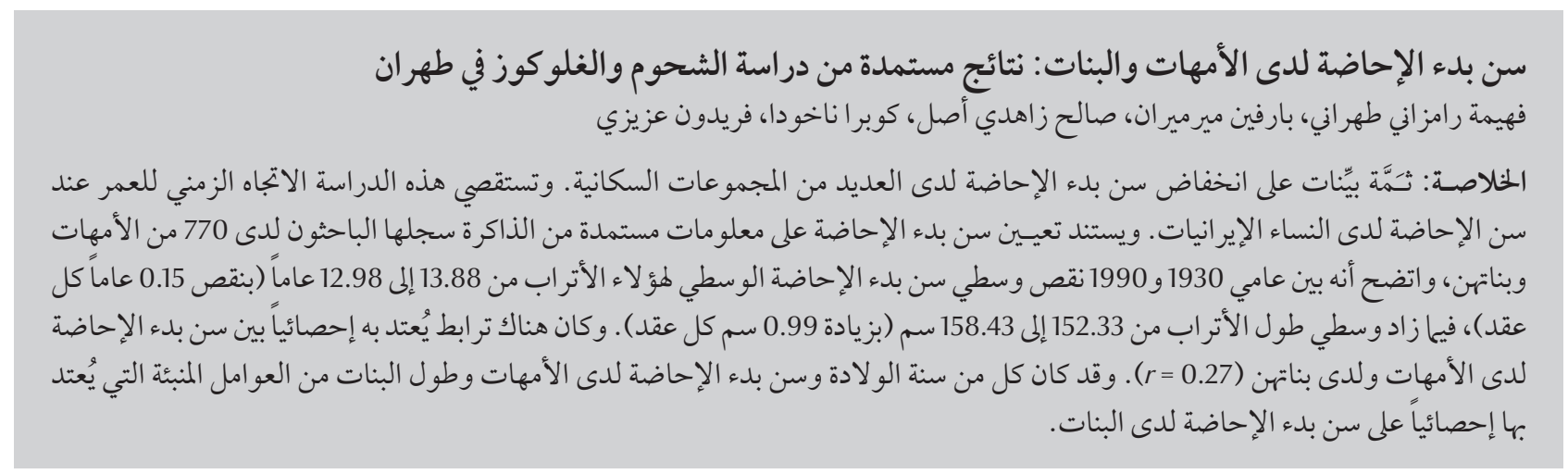

ABSTRACT There is some evidence for a decreasing age of menarche in many populations. This study examined the secular trend of age at menarche among Iranian women. Age at menarche based on recall information was recorded for 770 pairs of mother and daughters. Between 1930 and 1990 mean menarcheal age of this cohort of women decreased from 13.88 to 12.98 years (-0.15 years per decade) and mean height of the cohort increased from 152.33 to $158.43 \mathrm{~cm}$ (+0.99 cm per decade). There was a significant correlation between menarcheal age of mothers and their daughters $(r=0.27)$. Year of birth, mother's menarcheal age and daughter's height were significant predictors of daughter's menarcheal age.

Âge de la ménarche chez les mères et leurs filles, dans le cadre de l'étude sur les lipides et le glucose réalisée à Téhéran

RÉSUMÉ Certaines données montrent que l'âge de l'apparition des premières règles décroît dans de nombreuses populations. Cette étude analyse la tendance séculaire de l'âge de la ménarche chez les femmes iraniennes. L'âge de survenue des premières règles chez 770 groupes mère/filles a été enregistré d'après le souvenir qu'en avaient ces femmes. Entre 1930 et 1990, l'âge moyen de la ménarche pour la cohorte de femmes concernées est passé de 13,88 ans à 12,98 ans (- 0,15 an par décennie) et la taille moyenne de la cohorte a augmenté de 152,33 cm à 158,43 cm $(+0,99 \mathrm{~cm}$ par décennie). Une corrélation significative entre l'âge de la ménarche des mères et celui de leurs filles a été observée $(r=0,27)$. L'année de naissance, l'âge de la mère lors de la ménarche et la taille des filles sont des facteurs prédictifs significatifs de l'âge de la ménarche des filles. 


\section{Introduction}

Menarche is a late event in the sexual maturation of girls [1], its timing being influenced by many factors [2]. Age at menarche reflects numerous health aspects of a population including the timing of sexual maturation, growth and nutritional status and environmental conditions [3].

A positive change in menarcheal age over time has been reported by some studies, with a reduction rate of 2-3 months per decade reported in the United States of America and some European countries [3-9]; , other studies, however did not document any appreciable decrease in menarcheal age $[10,11]$. One review article mentioned that evidence supporting a decrease in the age of menarche was still unsubstantiated [12]. A secular trend towards an earlier age at menarche during the last few decades has been regarded as a positive indicator of a population's health status $[13,14]$.

In healthy, well-nourished girls, menarche is largely dependent on genetics [15]. Studies on the menarcheal age of twins, sisters and mother-and-daughter pairs suggest a significant genetic effect [16].

There are limited studies on age at menarche for Iranian girls, the secular trend of menarcheal age and the possibility of a mother-daughter correlation of menarcheal age has not been investigated extensively. The objectives of the current study were to examine the secular trend in age at menarche among women born during 1930-90 and to determine any mother-daughter correlations for age at menarche in the Tehran Lipid and Glucose Study (TLGS) population [17]. The TLGS is a prospective follow-up study, started in 1997, among 14000 individuals, both male and female, aged 3-69 years, selected randomly from one urban district of Tehran.

\section{Methods}

The sample for the present study included 770 pairs of mothers and daughters, 1540 individuals overall, who were selected for the study from the TLGS cohort [17]. Mothers were included if they had at least 1 daughter whose menstruation had begun prior to the initiation of the study and if data on menarcheal age were available for both mother and daughter. If any mother had more than 1 daughter meeting the inclusion criteria, the daughter whose name was first, based on alphabetical order, was chosen.

Interviews were conducted by a trained midwife. Each participant was asked: "At which age did you have your first menstrual period?" Probing questions such as "Do you remember what grade you were when your menstruation began?" for girls and "How many years after your first menstruation did you get married?" for mothers were used to help respondents remember the date. The same questions were asked 3 years later (second phase), to reconfirm the data on menarcheal age and the same answers were given by $83 \%$ of the subjects. Because errors in recalling age at menarche are likely to increase with age, menarcheal age was considered based on date provided at the first phase interview for participants giving different answers in these 2 phases. Since the month of menarche was not asked, we assumed that all respondents experienced their menarche at the midpoint of the year reported.

Girls were asked about the education level and occupational status of their parents; socioeconomic status was categorized based on the answers given, applying the Hollingshead index [18], which had been modified according to our standards. The index has scores for education level from no education (0) to university (4) and for occupation from none (0) to professional (4). The socioeconomic class was defined for this study as low (scores $0-8$ ) or high (scores 9-16).

Weight was measured with the women minimally clothed, without shoes, using a digital scale and recorded to the nearest $100 \mathrm{~g}$; height was measured in a standing position, without shoes, using a tape measure, while the shoulders were in a normal position. To reduce subjective error, all measurements were taken by the same female technician, who had been trained appropriately and was supervised by a general practitioner. It was assumed that height had not changed much since menarcheal age and that approximately $95 \%$ of height had been achieved at age of menarche, compared with mature height [19].

\section{Statistical analysis}

To determine changes in age at menarche between 1930 and 1990, the data were initially analysed by simple linear regression, with age at menarche as the dependent variable and year of birth as the sole covariate. Data were also stratified by year of birth and presented at 10-year intervals. Values are presented as mean and standard deviation (SD). Analysis of variance (ANOVA) was used to compare the data presented at 10-year intervals. The results were considered statistically significant at $P$ $<0.05$. Pearson correlation analysis was used to determine the relation between the menarcheal age of mothers and of their daughters.

The mean age of mothers and daughters at menarche in different socioeconomic groups were compared by 1-way ANOVA. Simple regression analysis was used to assess the prediction capability of menarcheal age of mother for their daughters.

Multiple linear regression analysis (stepwise method) was utilized to evaluate the predictors of menarcheal age of daughter as a dependent variable, using year of birth, menarcheal age of mother, height of mother and height of daughter as predictive variables. 
Statistical analyses were performed using SPSS, version 15 software.

\section{Results}

The secular trends in height and menarcheal age by year of birth for women born between 1930 and 1990 are shown in Figures 1 and 2. The mean menarcheal age of this cohort of women decreased by 0.90 years from 13.88 to 12.98 years during the past 60 years, showing a downward rate of 0.15 years per decade. The mean height of the cohort increased by $5.94 \mathrm{~cm}$ from 152.33 $\mathrm{cm}$ to $158.43 \mathrm{~cm}$ during the same period, an increase of $0.99 \mathrm{~cm}$ per decade. The results of a simple linear regression model with menarcheal age as the dependent variable and year of birth as the sole covariate demonstrated a significant association between the variables (regression coefficient for standardized variables, $\beta=0.08 ; P<0.001)$.

The mean age at menarche of mothers involved in the study was significantly higher [13.61 (SD 1.50) years] than the mean age at menarche of their daughters [13.17 (SD 1.36) years] ( $P$ $<0.001$; 95\% CI: 0.22-0.63) (Table 1). The mean menarcheal age for girls in the low socioeconomic group was 13.28 (SD 1.44) years compared with 13.00 (SD 1.21) years for girls with a high socioeconomic status, a significant difference between these 2 socioeconomic groups $(P=0.04)$.

A positive correlation was observed between menarcheal age of mothers and their daughters $(r=0.27, P<0.001)$. This correlation persisted independent of the socioeconomicstatus of daughters, being 0.38 for the high socioeconomic group and 0.22 for the low socioeconomic. The correlation between menarcheal age of mothers and daughters was also assessed using the simple regression analysis, considering the menarcheal age of daughter as a dependent variable and the menarcheal age of mother

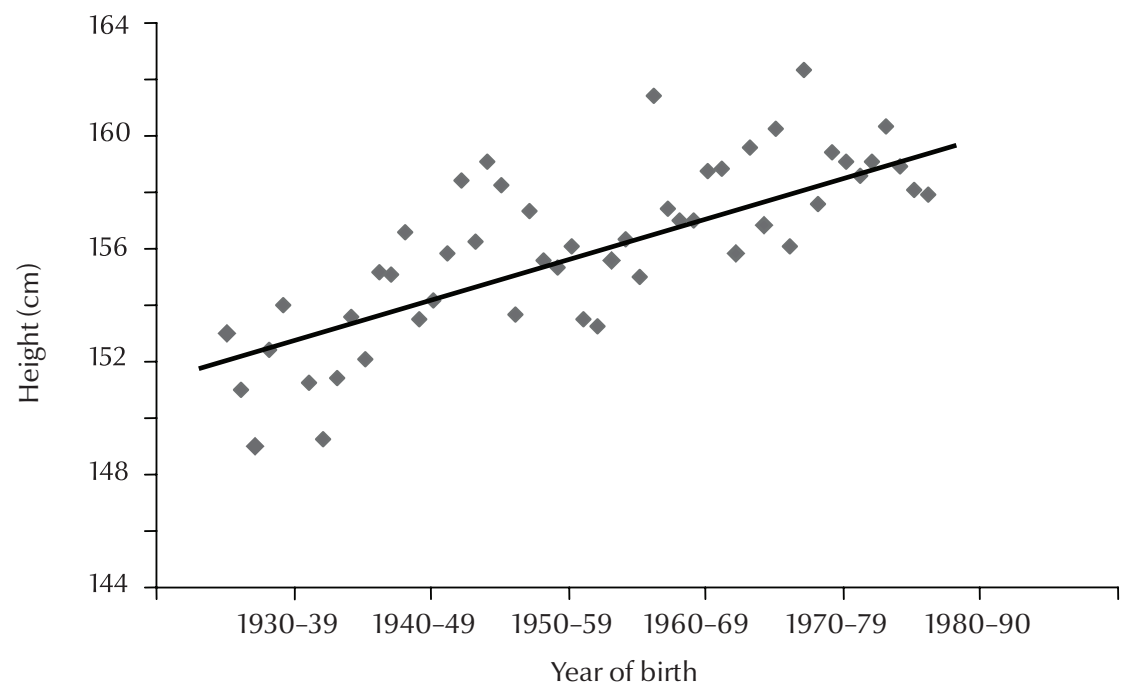

Figure 1 Secular trend in height by year of birth for a cohort of Tehran women born between 1930 and $1990(n=1540)$

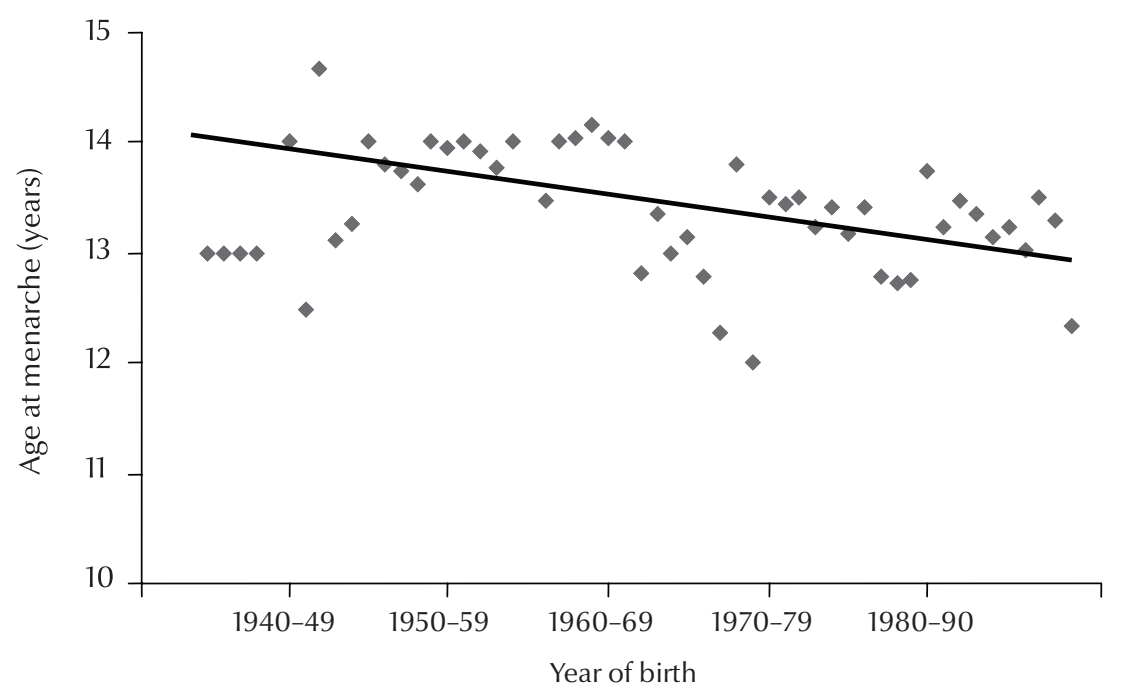

Figure 2 Secular trend in age at menarche by year of birth for a cohort of Tehran women born between 1930 and $1990(n=1540)$

as a predictive variable; the correlation coefficient of this model was $R=0.27\left(R^{2}\right.$ $=0.07 ; P<0.001)$ and the mother's age was a statistically significant predictive variable $(\beta=0.07 ; P<0.001)$.

The interpretation of the motherdaughter correlation may be confounded by the colinearity between the age of the subject and her recalled age at menarche and also socioeconomic changes over time. To correct for alterations in socioeconomic status. we assumed that change of height in a cohort over time reflects alterations in socioeconomic status [20]. The results of the multiple linear regression analysis using daughter's menarcheal age as the dependent variable and year of birth, mother's menarcheal age, mother's height and daughter's height as predictive variables are shown in Table 2 . The correlation coefficient of this model was $R=0.37\left(R^{2}=0.14 ; P<0.001\right)$. The statistically significant predictive variables were year of birth $(\beta=0.07 ; P<0.001)$, menarcheal age of mother $(\beta=0.23$; 


Table 1 Mean age at the time of the study and mean age at menarche of mother-
daughter pairs in the Tehran Lipid and Glucose Study
\begin{tabular}{|lccc}
\hline Croup & Current age (years) & Age at menarche (years) \\
& Mean (SD) & Range & Mean (SD) \\
Mothers $(n=770)$ & $44.84(7.26)$ & $29-70$ & $13.61(1.50)$ \\
Daughters $(n=770)$ & $18.62(4.29)$ & $11-30$ & $13.17(1.36)$
\end{tabular}

$P<0.001)$ and height of daughter $(\beta$ $=0.03 ; P=0.02$ ).

\section{Discussion}

In this paper we present for the first time data on a secular trend between 1930 and 1990 towards earlier age at menarche in Iranian women and on the close association of this trend with attained height. The mean menarcheal age of the cohort decreased by 0.15 years per decade while mean height increased by $0.99 \mathrm{~cm}$ per decade.

Although the secular trend of menarcheal age has been studied in many countries, there are conflicting data on this trend for earlier onset of puberty and menarche [21]. Studies from Denmark and The Netherlands have not shown any reduction in menarcheal age of the population since $1960[10,11]$. In contrast, a significant trend in the age of onset of puberty and menarche over time has been reported from Brazil, the USA, South China, Mexico and Korea [3-9,20].

A positive secular trend for height of the population has been shown in some

\begin{tabular}{|c|c|c|}
\hline \multicolumn{3}{|c|}{$\begin{array}{l}\text { Table } 2 \text { Multiple regression analysis of } \\
\text { the correlation between menarcheal } \\
\text { age of mothers and daughters, using } \\
\text { menarcheal age of daughter as the } \\
\text { dependent variable }\end{array}$} \\
\hline Variable & $\beta$-value & $P$-value \\
\hline Intercept & 6.76 & 0.003 \\
\hline Year of birth & 0.07 & $<0.001$ \\
\hline $\begin{array}{l}\text { Mother's } \\
\text { menarcheal age }\end{array}$ & 0.23 & $<0.001$ \\
\hline Mother's height & -0.17 & 0.21 \\
\hline Daughter's height & 0.03 & 0.02 \\
\hline
\end{tabular}

studies $[20,22]$. In the current study, the mean height of the cohort increased by $5.94 \mathrm{~cm}$, showing an upward rate of 0.99 $\mathrm{cm}$ per decade.

We used height as a proxy for socioeconomic status over time and assumed that current height was a suitable measure as approximately $95 \%$ of mature height is achieved by the age of menarche $[19,23]$. In the present study, menarcheal age was higher in girls with low socioeconomic status compared with girls with a high socioeconomic status. This agrees with some studies $[14,24]$, but not with others [13-15]. However, the menarcheal age of mothers was significantly higher than their daughters in all socioeconomic groups, a finding similar to that of the Ersoy et al. [15].

The correlation between the menarcheal age of mothers and their daughters in the current study was 0.27 using simple regression and 0.37 after multiple regression, which is comparable to figures of 0.23 to 0.39 in other studies $[15,25,26]$. In the majority of these studies the association also persisted after controlling for confounding variables. We used multiple regression analysis because the mother-daughter correlation in menarcheal age could be confounded by the colinearity between the age of the woman and her recalled age at menarche (older subjects tend to recall an older age of menarcheal age [27]) and also by improvements in the socioeconomic status of the community over time [27]. We used height as a variable, as changes in the height a population over time can indirectly show improvement of socioeconomic status [20]. We also entered the height of both mothers and their daughters into the model in order to include the genetic component of height. In our population, variations in height (as a proxy for socioeconomic status) or the cohort effect of mothers' recall of age at menarche did not affect the correlation of menarcheal age between mothers and daughters. Our finding, however, contrasts with that of Cameron and Nagdee who found that the motherdaughter correlation of age at menarche became nonsignificant after controlling for the maternal age at which mothers recalled their menarcheal age [25].

The most important limitation of this tudy was the use of self-reported menarcheal age and the possible inaccuracies associated with mothers attempting to recall the date several decades later. As would be expected, the ability to recall accurately menarcheal age decreases dramatically over time [28]. Despite this, the correlations between recalled and actual recorded menarcheal age over periods of up to 10 years have been shown to be generally high $(r>0.75)$ $[27,29,30]$. We can argue that in a conservative and religious society such as the Islamic Republic of Iran, menarche is an important growth milestone that is well remembered by women. We reported the mean age at menarche of the cohort not the individual age at menarche and we confirmed the reliability of the data on menarcheal age by asking the women the same questions 3 years later. Therefore we can argue that the effect of recall error may be minimal.

Another limitation of this study was that the month of menarche was not used since the majority of women had difficulty in recalling it correctly. Data on the socioeconomic status of mothers at the time of menstruation was not available. Also we did not evaluate the effect of other important variables such as participants' body mass index, physical activity or nutrition on menarcheal age.

It needs to be mentioned that the current analyses were based on data from a single community in Tehran 
and, since menarcheal age can vary by location, it may not be possible to generalize these results to other communities in the Islamic Republic of Iran.

To conclude, it is recommended that trends in menarcheal age in relation to trends in socioeconomic status and industrial growth in the Islamic Republic of Iran be observed and monitored in the next few decades to confirm the present findings in different communities.

\section{Acknowledgements}

We thank the National Council of Scientific Research of the Islamic Republic of Iran for approval of this project and its funding as a national research project.

\section{References}

1. Malina RM et al. Family size and age at menarche in athletes. Medicine and science in sports and exercise, 1997, 29:99-106.

2. Ekele BA, Udoeyop EU, Otubu JA. Age at menarche amongst school girls in a high altitude Nigerian town. West African journal of medicine, 1996, 15:170-2.

3. Chumlea WC et al. Age at menarche and racial comparisons in US girls. Pediatrics, 2003, 111:110-3.

4. Wyshak G, Frisch RE. Evidence for a secular trend in the age of menarche. New England journal of medicine, 1982, 306:1033-5.

5. Anderson SE, Must A. Interpreting the continued decline in the average age at menarche: results from two nationally representative surveys of US girls studied 10 years apart. Journal of pediatrics, 2005, 147:753-60.

6. Freedman DS, Khan LK, Serdula MK. Relation of menarche to race, time period, and anthropomorphic dimensions: the Bogolusa Heart Study. Pediatrics, 2002, 110:110-7.

7. Mahachoklertwattana P, Suthutvoravut U, Charoenkiatkul S. Earlier onset of pubertal maturation in Thai girls. Journal of the Medical Association of Thailand, 2002, 85(Suppl. 4):S1127-34.

8. Huen KF et al. Secular trend in the sexual maturation of southern Chinese girls. Acta paediatrica, 1997, 86:1121-4.

9. Malina RM et al. Secular change in age at menarche in rural Oaxaca, southern Mexico: 1968-2000. Annals of human biology, 2004, 31:634-46.

10. Juul A et al. Pubertal development in Danish children: comparison of recent European and US data. International journal of andrology, 2006, 29:247-55.

11. Mul D et al. Pubertal development in The Netherlands 19651997. Pediatric research, 2001, 50:479-86.

12. Colman L, Colman J. The measurement of puberty: a review. Journal of adolescence, 2002, 25:535-50.

13. Ersoy B et al. Effects of different socioeconomic conditions on menarche in Turkish female students. Early human development, 2006, 76:115-25.

14. Rimpela AH, Rimpela MK. Towards an equal distribution of health? Socioeconomic and regional differences of the secular trend of the age of menarche in Finland from 1979 to 1989. Acta paediatrica, 1993, 82:87-90.

15. Ersoy B et al. The factors affecting the relation between the menarcheal age of mother and daughter. Child: care, health and development, 2005, 31:303-8.
16. Malina RM, Bouchard C. Growth, maturation and physical activity. Champaign, Illinois, Human Kinetics Books, 1991.

17. Azizi F et al. Tehran Lipid and Glucose study: rational and design. CVD prevention, 2001, 3:121-7.

18. Hollingshead AB. Two factor index of social position. New Haven, Connecticut, Hollingshead, 1957.

19. Tsuzaki $S$ et al. Lack of linkage between height and weight and age at menarche during the secular shift in growth of Japanese children. Annals of human biology, 1989, 16:429-36.

20. Hwangy J-Y et al. Secular trend in age at menarche for South Korean women born between 1920 and 1986: the Ansan Study. Annals of human biology, 2003, 30:434-42.

21. Kaplowitz P. Pubertal development in girls: secular trends. Current opinion in obstetrics and gynecology, 2006, 18(5):487-91.

22. Lin WS et al. The menarcheal age of Chinese girls. Annals of human biology, 1992, 19:503-12.

23. Chang $\mathrm{SH}$ et al. Height and weight change across menarche of schoolgirls with early menarche. Archives of pediatrics and adolescent medicine, 2000, 154:880-4.

24. Wronika I, Pawlin R, Chamara S. Menarcheal age and socioeconomic factors in Poland. Annals of human biology, 2005, 32:630-8.

25. Cameron N, Nagdee I. Menarcheal age in two generations of South African Indians. Annals of human biology, 1996, 23:113-9.

26. Pouta A et al. Mothers and daughters: intergenerational patterns of reproduction. European journal of public health, 2005, 15:195-9.

27. Koprowski C, Coates, Bernstein L. Ability of young women to recall past body size and age at menarche. Obesity research, 2001, 9:478-85.

28. Finlay F, Jones R. Menarcheal age of mothers and daughters. Child: care, health and development, 2006, 31:121.

29. Bergesten-Brucefors A. Accuracy of recalled age at menarche. Annals of human biology, 1976, 3:71-3.

30. Koo MN, Rohan TE. Accuracy of short term recall of age at menarche. Annals of human biology, 1997, 24:61-4. 